REVIEW ARTICLE

\title{
Maternal Mortality: Tragedy for Developing Countries and Shame for Developed World
}

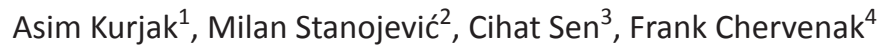

\begin{abstract}
Aim: To present the data from United Nations 2005 and 2015 Millennium Development Goals (MDG) reports.

Results: The World is faced with the increasing problem of inequality. That is why millennium declaration was signed in the year 2000. The United Nations millennium declaration embodies an agreement that developing countries will work to maintain sound economies, to ensure their own development and to address human and social needs. Developed countries, in turn, agree to support poorer countries through aid, trade, and debt relief. A meaningful partnership between rich and poor must also address developing countries' need for technology, medicines, and jobs for their populations, particularly for the growing ranks of young people. In this paper, two MDG reports from 2005 to 2015 were presented with the analysis of the reasons for which the targets of MDG were not met and how World Association of Perinatal Medicine, International Academy of Perinatal Medicine, lan Donald School of Medical Ultrasound and International Society Fetus as a Patient can help.
\end{abstract}

Conclusion: More political efforts should be made in order to improve health of the mothers and infants in order to make this world sustainable. Keywords: Maternal mortality rate, Millennium development goals report, Sustainable development, Under-five mortality, United Nations. Donald School Journal of Ultrasound in Obstetrics and Gynecology (2020): 10.5005/jp-journals-10009-1621

\section{INTRODUCTION}

In the well-organized document, the millennium development goals (MDG) report 2005, United Nations office from New York, presented in detail most of the hot topics in the field of reduction of high rate of maternal mortality.

The MDG, which range from halving extreme poverty to putting all children into primary school and stemming the spread of infectious diseases such as HIV/AIDS, all by 2015, have become globally accepted benchmarks of broader progress, embraced by donors, developing countries, civil society, and major development institutions alike.

It was hoped that these goals can be met by 2015-but only if all involved break with business as usual and dramatically accelerate and scale up action now. ${ }^{1}$

In a very analytic foreword, former secretary general of United Nations Kofi Annan sent number of valuable messages:

The adoption of the MDG, drawn from the United Nations millennium declaration, was a seminal event in the history of the United Nations. It constituted an unprecedented promise by World leaders to address, as a single package, peace, security, development, human rights, and fundamental freedoms. ${ }^{1}$

"We will not enjoy development without security, we will not enjoy security without development, and we will not enjoy either without respect for human rights. Unless all these causes are advanced, none will succeed."

The eight MDG form a blueprint agreed by all the World's countries, and all the World's leading development institutions-a set of simple but powerful objectives that every man and woman in the street, from New York to Nairobi to New Delhi, can easily support and understand.

Since their adoption, the goals have galvanized unprecedented efforts to meet the needs of the World's poorest.'

Why are the MDG so different? There are four reasons. ${ }^{1}$

\begin{abstract}
1,2Department of Obstetrics and Gynecology Medical School University of Zagreb, Clinical Hospital Sveti Duh, Zagreb, Croatia

${ }^{3}$ Department of Obstetrics and Gynecology, İstanbul UniversityCerrahpaşa, Istanbul, Turkey

${ }^{4}$ Department of Obstetrics and Gynecology, Lenox Hill Hospital, Zucker School of Medicine at Hofstra/Northwell, USA

Corresponding Author: Asim Kurjak, Department of Obstetrics and Gynecology Medical School University of Zagreb, Clinical Hospital Sveti Duh, Zagreb, Croatia, Phone: +385 1 4684349, e-mail: asim. kurjak@public.carnet.hr

How to cite this article: Kurjak A, Stanojević M, Sen C, et al. Maternal Mortality:Tragedy for Developing Countries and Shame for Developed World. Donald School J Ultrasound Obstet Gynecol 2020;14(1):17-27.

Source of support: Nil

Conflict of interest: None
\end{abstract}

First, the MDG are people-centerd, time-bound, and measurable.

Second, they are based on a global partnership, stressing the responsibilities of developing countries for getting their own house in order, and of developed countries for supporting those efforts.

Third, they have unprecedented political support, embraced at the highest levels by developed and developing countries, civil society and major development institutions alike.

Fourth, they are achievable.

This progress report is the most comprehensive accounting to date on how far we have come, and how far we have to go, in each of the World's regions. ${ }^{1}$ It reflects a collaborative effort among a large number of agencies and organizations within and outside the United Nations system. All have provided the most up-to-date data possible in their areas of responsibility, helping thereby to achieve clarity and consistency in the report.

Above all, the report shows us how much progress has been made in some areas and how large an effort is needed to meet the

() The Author(s). 2020 Open Access This article is distributed under the terms of the Creative Commons Attribution 4.0 International License (https://creativecommons. org/licenses/by-nc/4.0/), which permits unrestricted use, distribution, and non-commercial reproduction in any medium, provided you give appropriate credit to the original author(s) and the source, provide a link to the Creative Commons license, and indicate if changes were made. The Creative Commons Public Domain Dedication waiver (http://creativecommons.org/publicdomain/zero/1.0/) applies to the data made available in this article, unless otherwise stated. 
MDG in others. ${ }^{1}$ If current trends persist, there is a risk that many of the poorest countries will not be able to meet many of them. ${ }^{1}$ Considering how far we have come, such a failure would mark a tragically missed opportunity. ${ }^{1}$ This report shows that we have the means at hand to ensure that nearly every country can make good on the promises of the goals. ${ }^{1}$ Our challenge is to deploy those means. ${ }^{1}$

"Let us be clear about the costs of missing this opportunity: millions of lives that could have been saved will be lost; many freedoms that could have been secured will be denied; and we shall inhabit a more dangerous and unstable World."

\section{Short Description of the Eight MDG Goal I: Eradicate Extreme Poverty and Hunger}

It is a sad fact that for more than 1 billion people who subsist on less than $\$ 1$ a day (Fig. 1). ${ }^{1}$ More than 800 million people have too little to eat to meet their daily energy needs. ${ }^{1}$ For young children, the lack of food can be perilous since it retards their physical and mental development and threatens their very survival. ${ }^{1}$ More than a quarter of children under age 5 in developing countries are malnourished (Fig. 2). ${ }^{1}$
There were 815 million hungry people in the developing World in 2002-9 million less than in 1990. Yet, in the worst-affected regions-sub-Saharan Africa and Southern Asia-the number of hungry people has increased by tens of millions. Growing populations and poor agricultural productivity have been the main reasons for food shortages in these regions. ${ }^{1}$ Most of the World's hungry live in rural areas and depend on the consumption and sale of natural products for both their income and their food (Fig. 3). ${ }^{1}$

Efforts to eradicate poverty and hunger are frequently set back by conflict and natural disasters. Hunger and poverty (Figs 4 and 5), in turn, can provide fertile ground for conflict, especially when combined with factors such as inequality, and make being prepared to cope with disasters more difficult. ${ }^{1}$

\section{Goal II: Achieve Universal Primary Education}

Education gives people choices regarding the kind of lives they wish to lead. It enables them to express themselves with confidence in their personal relationships, in the community and at work. ${ }^{1}$ The loss of potential does not affect children alone. Education, especially for girls, has social and economic benefits for society as a whole. Educated women have more economic opportunities and engage more fully in public life. ${ }^{1}$ As mothers, they tend to have fewer and

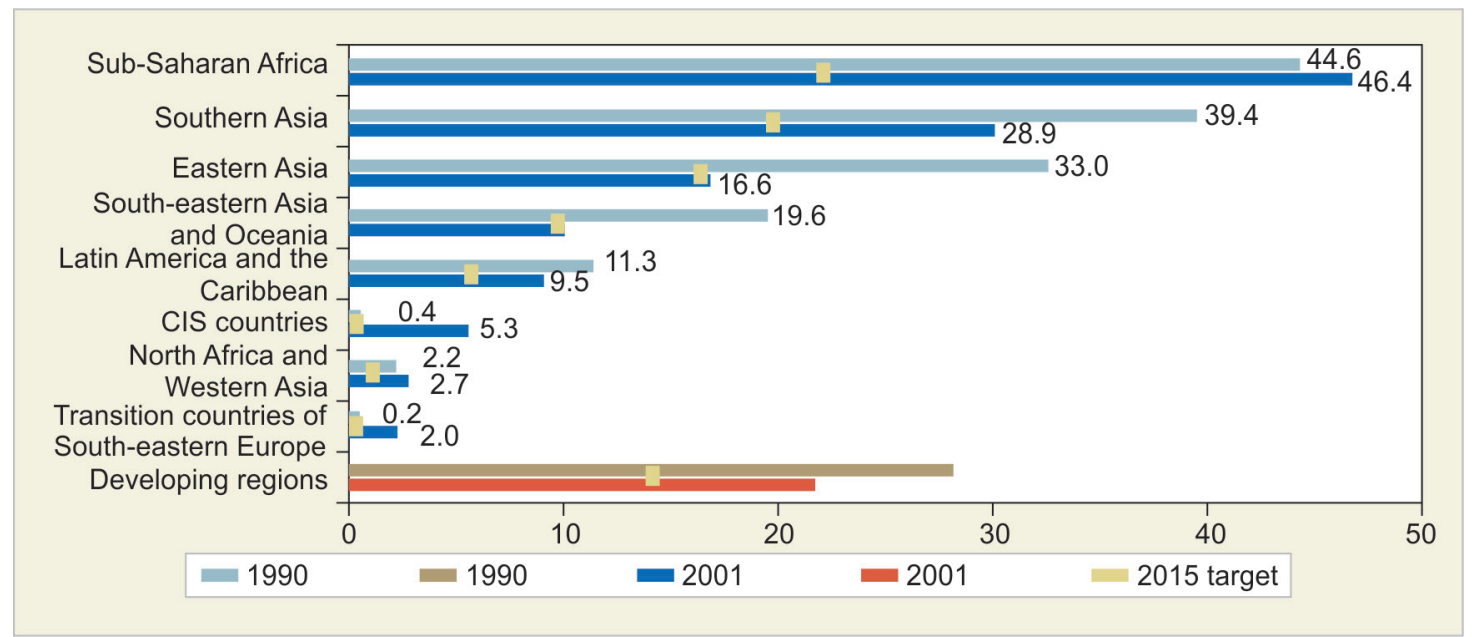

Fig. 1: Proportion of people living on less than $\$ 1$ a day in 1990 and 2001 in different regions of the World ${ }^{1}$

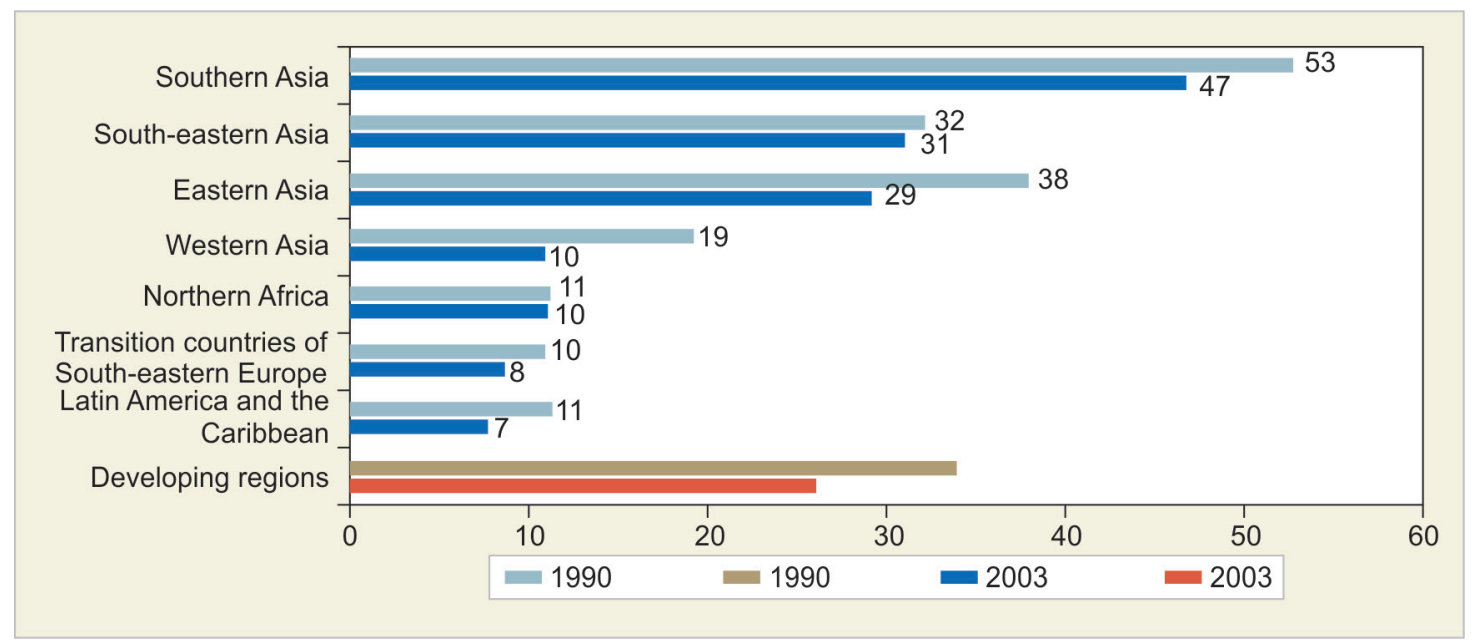

Fig. 2: Proportion of children under age 5 from different regions of the World who are underweight in the year 1990 and $2003^{1}$ 


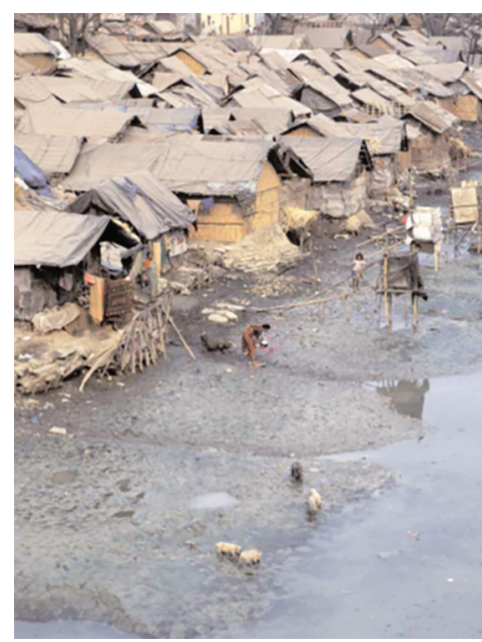

Fig. 3: Village in sub-Saharan Africa where the poverty and hunger are common $^{1}$

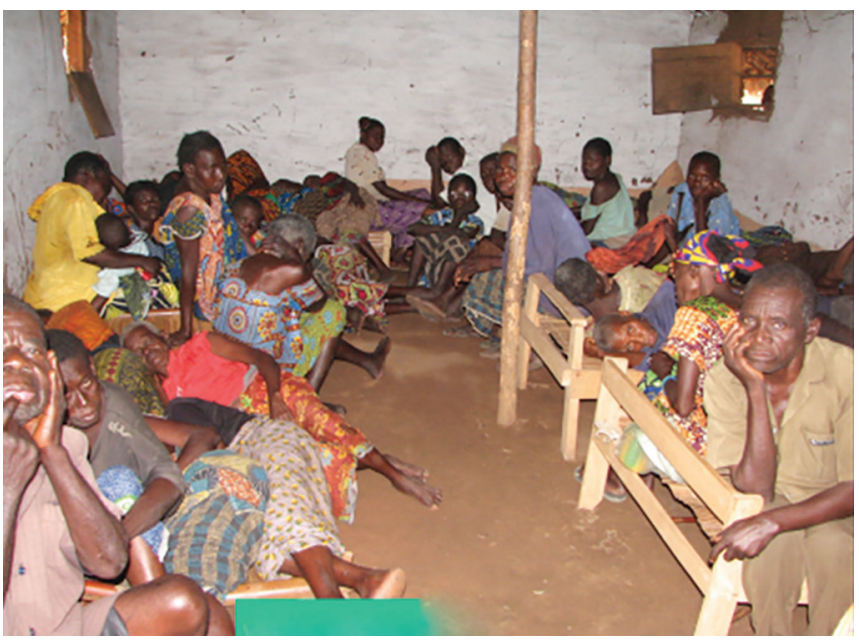

Fig. 5: Members of the family at usual African maternity (outside ward)

healthier children who are more likely to attend school. ${ }^{1}$ All of these benefits are key to breaking the cycle of poverty (Fig. 6). ${ }^{1}$

Of the 115 million children out of school in developing countries in 2001, some had dropped out, others had never been enrolled at all (Fig. 7). ${ }^{1}$ In Mali, for instance, almost none of the $61 \%$ of children out of school have ever attended school consistently. ${ }^{1}$ In most developing regions, girls are less likely than boys to stay in school. ${ }^{1}$

In all developing regions, except Latin America and the Caribbean and Eastern and South-eastern Asia, girls are less likely than boys to remain in school. ${ }^{1}$ The gap between girls and boys is greatest in the 22 countries where fewer than $60 \%$ of children complete their primary education. ${ }^{1}$

\section{Goal III: Promote Gender Equality and Empower Women}

Gender equality is a human right and at the heart of achieving the MDG. ${ }^{1}$ It is a prerequisite to overcoming hunger, poverty, and disease. ${ }^{1}$ This means equality at all levels of education and in all areas of work, equal control over resources, and equal representation in public and political life. ${ }^{1}$ Achieving parity in education-in primary school and beyond-is critical if women are to engage fully in society and the global economy. ${ }^{1}$ But in too many countries, girls

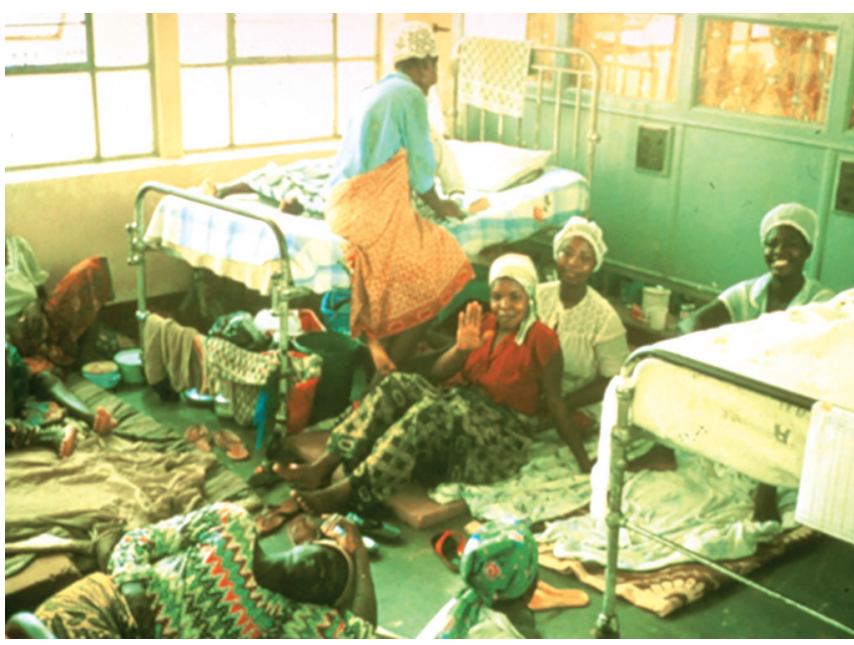

Fig. 4: Usual African maternity (inside ward)

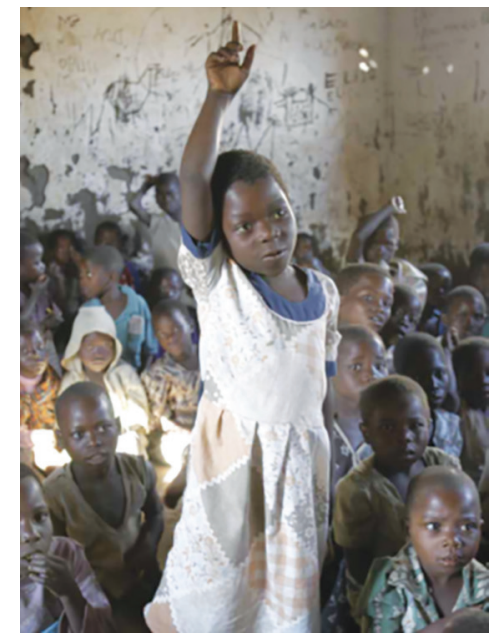

Fig. 6: Conditions at school in Africa ${ }^{1}$

are left behind (Fig. 8). ${ }^{1}$ Figure 9 showing adolescent girl taking care of her child in developing country. ${ }^{1}$

\section{Goal IV: Reduce Child Mortality}

The death of a child is a tragic loss. Yet, every year, almost 11 million children die-that is, 30,000 children a day-before their fifth birthday. ${ }^{1}$ Under-five mortality rate has slow down from 1990 to 2003, and probably targets set by MDG for 2015 will not be met, as shown in Figure 10.

Education, especially for girls and mothers, saves children's lives. Raising incomes can help, but little will be achieved unless services reach those who need them most (Fig. 11). ${ }^{1}$

\section{Goal V: Improve Maternal Health}

Giving birth should be a time of joy. But for more than half a million women each year, pregnancy and childbirth end in death (Fig. 12). ${ }^{1}$ Twenty times as many women suffer serious injuries or disabilities, which, if untreated, can cause lifelong pain and humiliation. ${ }^{1}$ A mother's death can be particularly devastating to the children left behind, who are more apt to fall into poverty and to become the objects of exploitation. ${ }^{1}$ Countries with already low levels of maternal mortality have made further progress. ${ }^{1}$ But this is not enough. Reductions in the worst-affected countries will require additional 


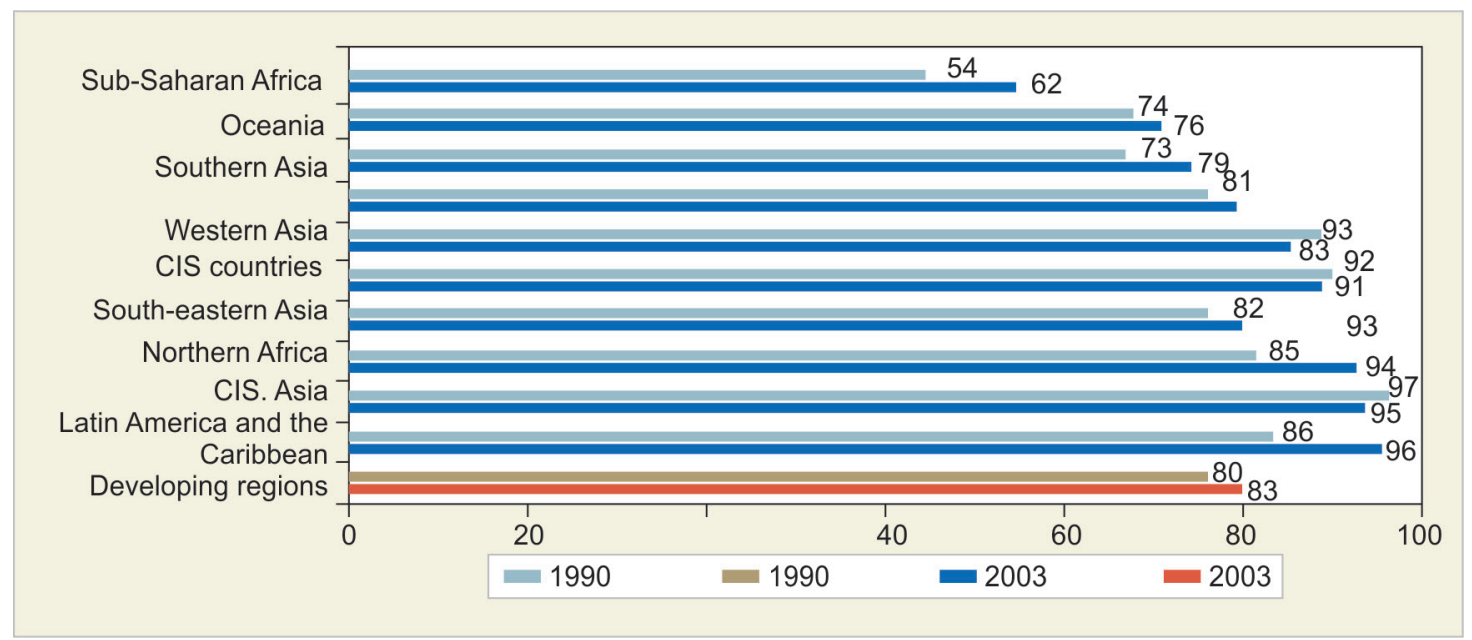

Fig. 7: Net enrollment ratio in primary education, 1990/1991 and 2001/2002 in different regions of the World (percentage) ${ }^{1}$

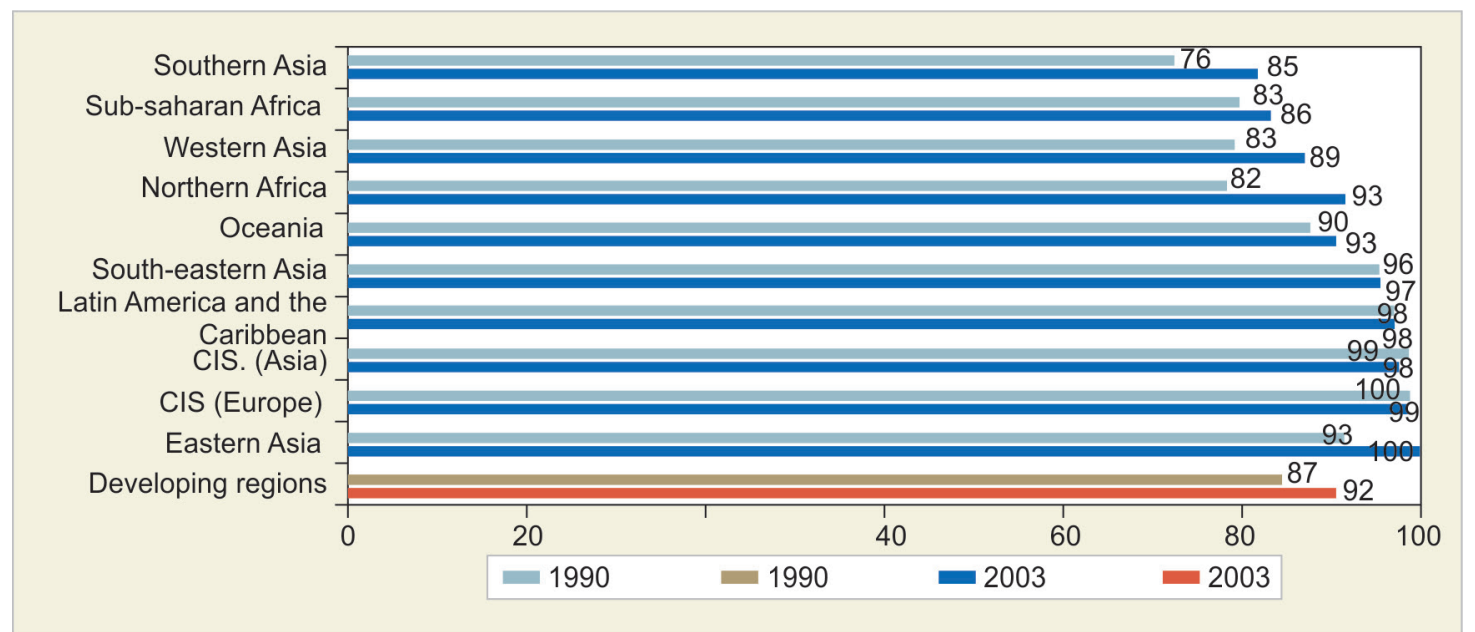

Fig. 8: Girl's primary school enrollment ratio in relation to boys' in 1990/1991 and 2001/2002 (girls per 100 boys) in different regions of the World'

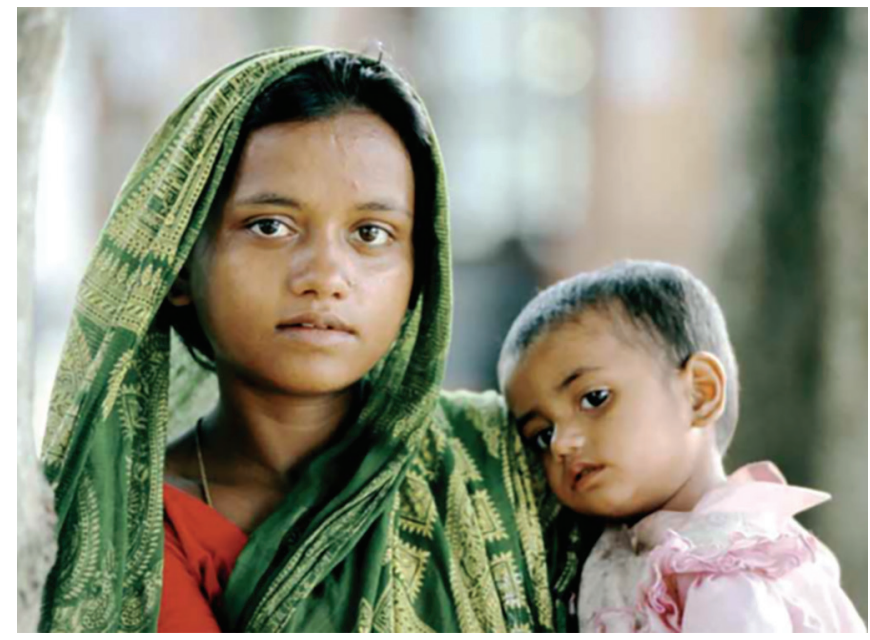

Fig. 9: Adolescent girl taking care of her child in developing country ${ }^{1}$

resources to ensure that the majority of births are attended by doctors, nurses, or midwives who are able to prevent, detect, and manage obstetric complications (Fig. 13). ${ }^{1}$ When problems do arise, women must be able to reach a fully equipped medical facility in time. Universal access to reproductive healthcare, including family planning, is the starting point for maternal health. ${ }^{1}$ Figure 14 shows how fertility rates have been decreasing in the World in the last 50 years and with projections to the year 2030. It is particularly important for addressing the needs of the 1.3 billion young people about to begin their reproductive lives. Currently, 200 million women have an unmet need for safe and effective contraceptive services. ${ }^{1}$

In 2000, the average risk of dying during pregnancy or childbirth in the developing World was 450 per 100,000 live births. In countries where women tend to have many children, they face this risk many times. Thus, the chances of dying during pregnancy or childbirth over a lifetime are as high as 1 in 16 in sub-Saharan Africa, compared with 1 in 3,800 in the developed World. ${ }^{1}$ This lifetime risk could be substantially reduced if women had the family planning services they desire. ' Once a woman is pregnant, it is essential that she has good medical care and access to emergency obstetric-care facilities in case of unexpected complications. ${ }^{1}$

Success is possible, even in poorer countries.

Although it is one of the poorest countries in the World, Bangladesh was able to substantially reduce maternal mortality by focusing on skilled birth attendants, access to emergency obstetric care, and expanded family planning programs. ${ }^{1}$ In Egypt, maternal mortality was cut in half in only 8 years. ${ }^{1}$ This extraordinary 


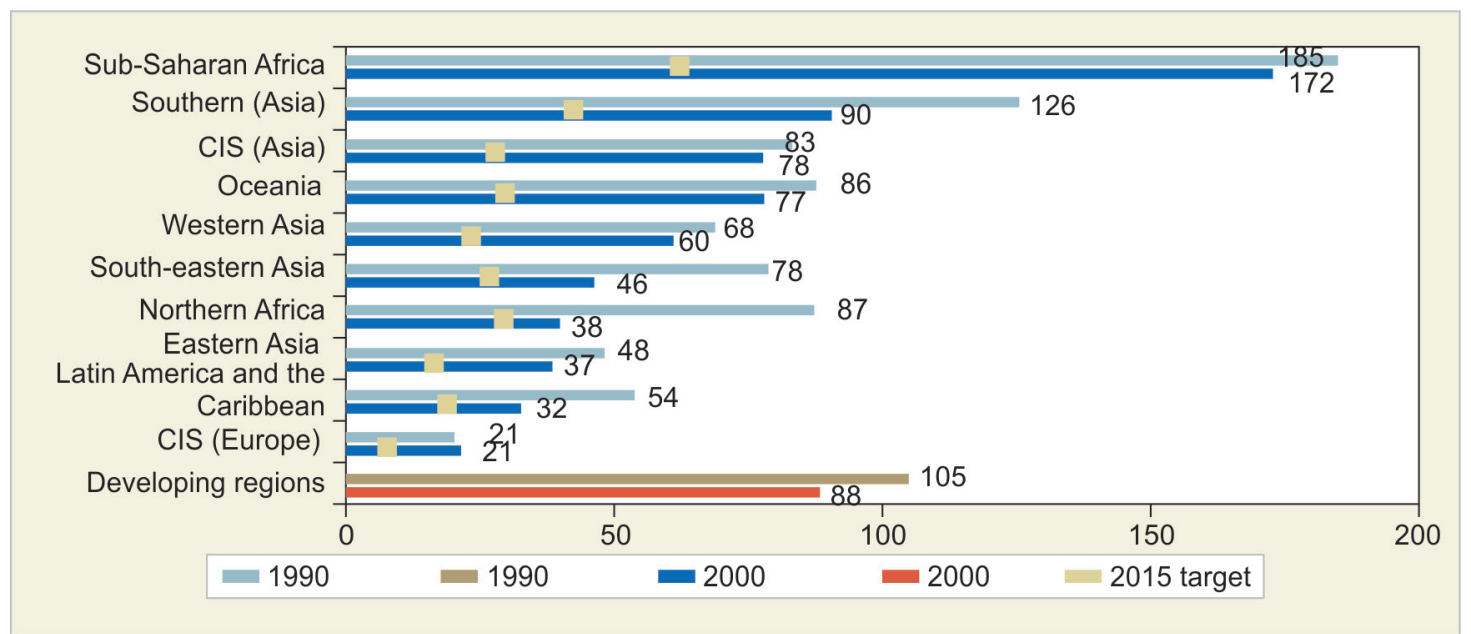

Fig. 10: Under-five mortality rate per 1,000 births in 1990 and 2003 in the regions of the World with targets set by MDG for $2015^{1}$

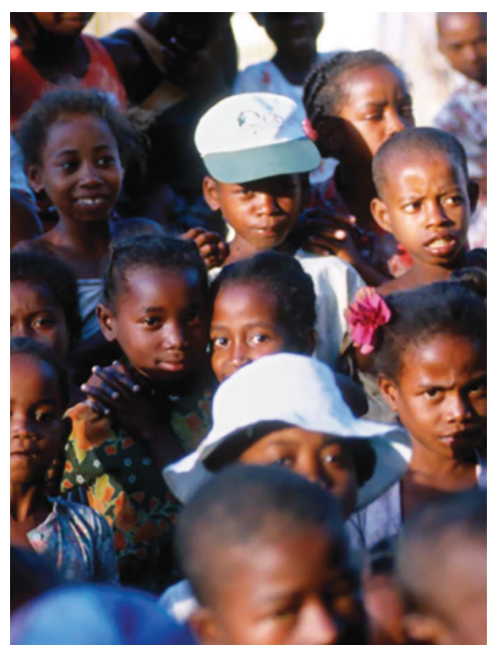

Fig. 11: Children whose needs in developing countries should be addressed $^{1}$

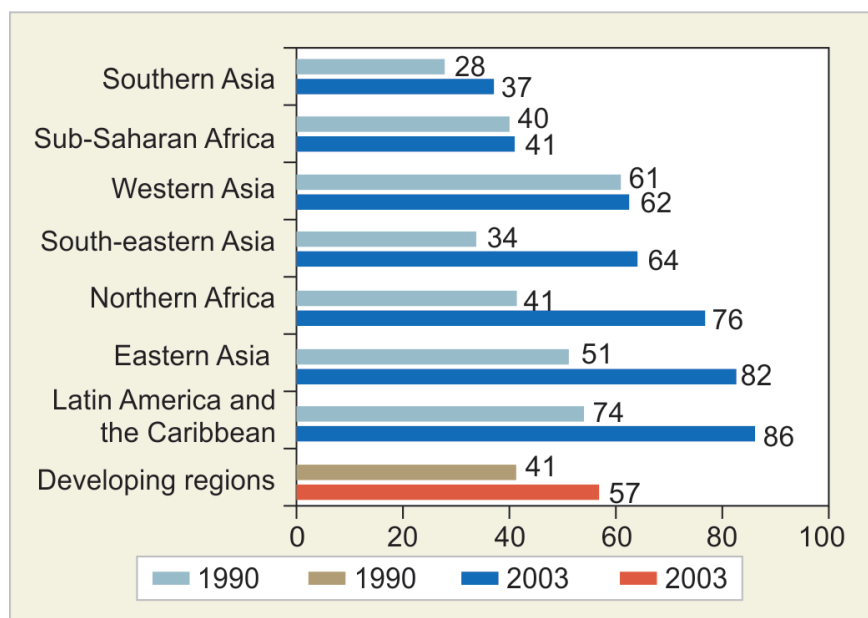

Fig. 13: Proportion of deliveries attended by skilled healthcare personnel in 1990 and 2003 (percentage) $^{1}$

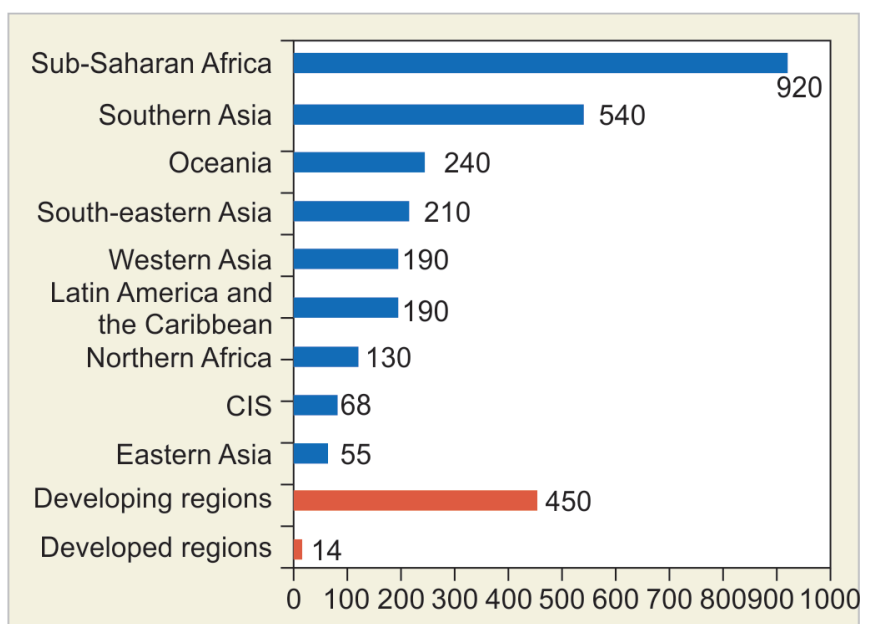

Fig. 12: Maternal mortality ratio per 100,000 live births in the year $2000^{1}$

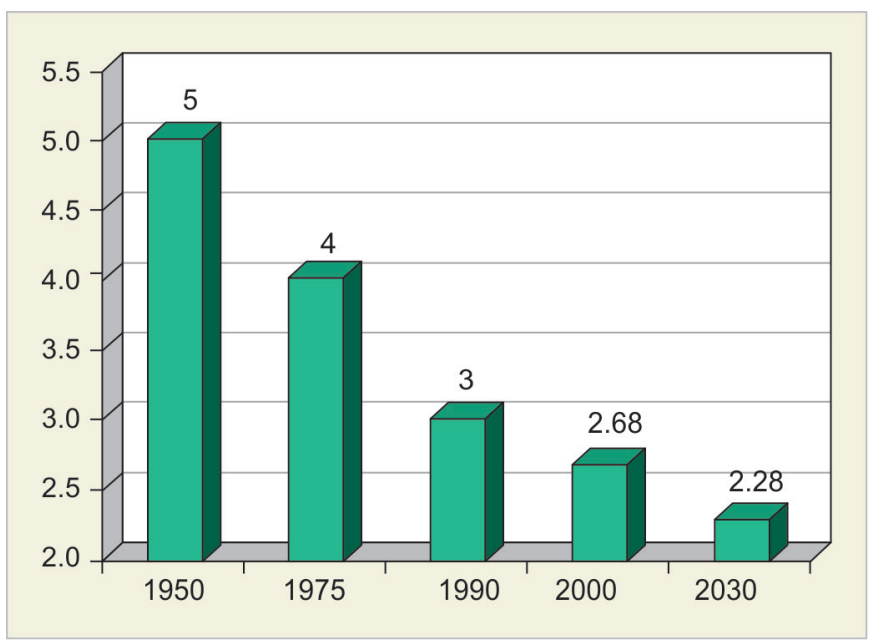

Fig. 14: World fertility rates from 1950 to 2000 , with the projections to 2030 
accomplishment was the result of a comprehensive program to boost the quality of medical care, especially the management of obstetric complications, and to ensure skilled attendants at births. ${ }^{1}$ Attention was also focused on mobilizing community support for women during pregnancy and childbirth and addressing reproductive health needs, including family planning. ${ }^{1}$ Impressive results have been achieved in India! ${ }^{1}$

Advances were made in most developing regions between 1990 and 2003 in providing medically skilled attendants at birth (Fig. 13). ${ }^{1}$ Major improvements were achieved in South-Eastern Asia, Northern Africa, and Eastern Asia, but there was no change in sub-Saharan Africa, where maternal mortality is highest. ${ }^{1}$ Though progress continues in Southern Asia, it has the lowest level of professional care at birth in the World. ${ }^{1}$ In every region, the presence of skilled birth attendants is lower in rural than in urban areas. ${ }^{1}$ Professional care at birth is one of the several factors that can lower maternal mortality, along with access to emergency obstetric care. ${ }^{1}$ To be effective, emergency facilities, however, must be stocked with essential drugs, equipment and supplies. ${ }^{1}$

\section{Goal VI: Combat HIV/AIDS, Malaria, and Other Diseases}

In the 25 years since it was first reported, AIDS has become the leading cause of premature death in sub-Saharan Africa and the fourth largest killer worldwide (Fig. 15). ${ }^{1}$ More than 20 million people have died around the World since the epidemic began. ${ }^{1}$ And by the end of 2004, an estimated 39 million people were living with HIV. In addition to the incalculable human suffering that AIDS has wrought, the epidemic has reversed decades of development progress in the worst-affected countries. ${ }^{1}$ Almost no country has escaped its wrath. But there are countries that are fighting backand winning. ${ }^{1}$ Thailand and Uganda have shown that infection rates can be reversed with vision and leadership. ${ }^{1}$ They provide an example to other countries caught in the grip of AIDS. ${ }^{1}$

A protection from malaria can be achieved by simple net use (Fig. 16). ${ }^{1}$

\section{Goal VII: Ensure Environmental Sustainability}

Environmental sustainability means using natural resources wisely and protecting the complex ecosystems on which our

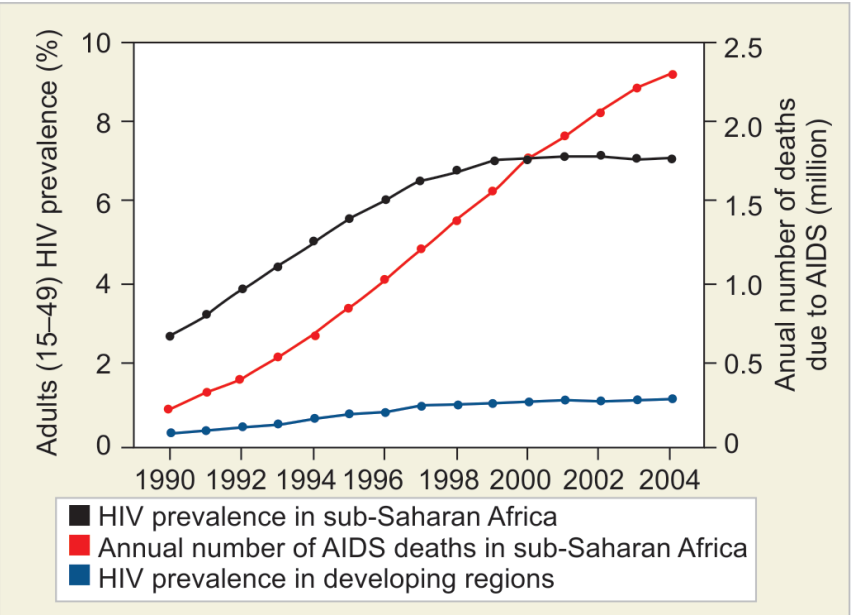

Fig. 15: HIV prevalence in adults aged 15-49 in sub-Saharan Africa and all developing regions (percentage) and number of AIDS deaths in subSaharan Africa (million), 1990-2004 survival depends. ${ }^{1}$ But sustainability will not be achieved with current patterns of resource consumption and use (Fig. 17). ${ }^{1}$ Land is becoming degraded at an alarming rate. ${ }^{1}$ Plant and animal species are being lost in record numbers. ${ }^{1}$ The climate is changing, bringing with it threats of rising sea levels and worsening droughts and floods. ${ }^{1}$ Fisheries and other marine resources are being overexploited. ${ }^{1}$ The rural poor are most immediately affected because their day-to-day subsistence and livelihoods more often depend on the natural resources around them. ${ }^{1}$ Though the exodus to urban areas has reduced pressure on rural lands, it has increased the number of people living in unsafe and overcrowded urban slums. ${ }^{1}$ In both urban and rural areas, billions of people lack safe drinking water and basic sanitation. ${ }^{1}$

\section{Goal VIII: Develop a Global Partnership for Development}

At the heart of the MDG is the understanding that fighting poverty (Fig. 18) is a collective undertaking and that all countries have a stake in the results. ${ }^{1}$ Primary responsibility to achieve the goals rests with developing countries, but international support is critical, especially for the poorest countries and for countries handicapped by geographical isolation. ${ }^{1}$ Moreover, in an interdependent World economy, open avenues for trade, international financial stability, and the spread of technology are needed to enable developing countries to seize opportunities for accelerated and sustained development. ${ }^{1}$ The United Nations millennium declaration embodies an agreement that developing countries will work to maintain sound economies, to ensure their own development and to address human and social needs. ${ }^{1}$ Developed countries, in turn, agree to support poorer countries through aid, trade, and debt relief. A meaningful partnership between rich and poor must also address developing countries' need for technology, medicines, and jobs for their populations, particularly for the growing ranks of young people. ${ }^{1}$

\section{InSTEAD OF CONCLUSION}

The MDG were derived from the United Nations millennium declaration, adopted by 189 nations in 2000. ${ }^{1}$ Most of the goals and targets were set to be achieved by the year 2015 on the basis of the global situation during the 1990s. ${ }^{1}$ It was during that decade

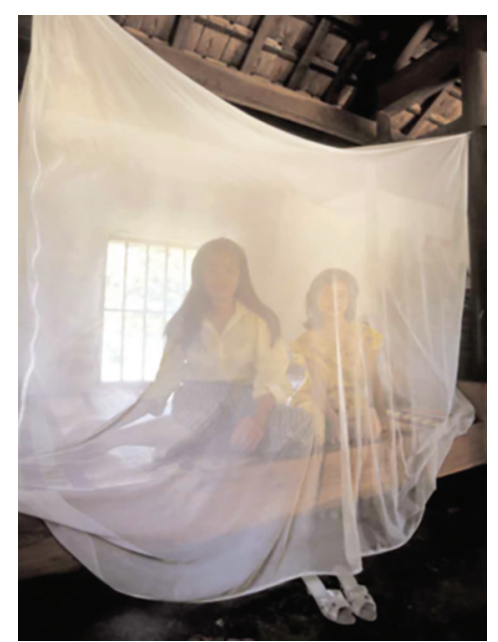

Fig. 16: In countries where malaria is the problem, protection from mosquitos by net ${ }^{1}$ 


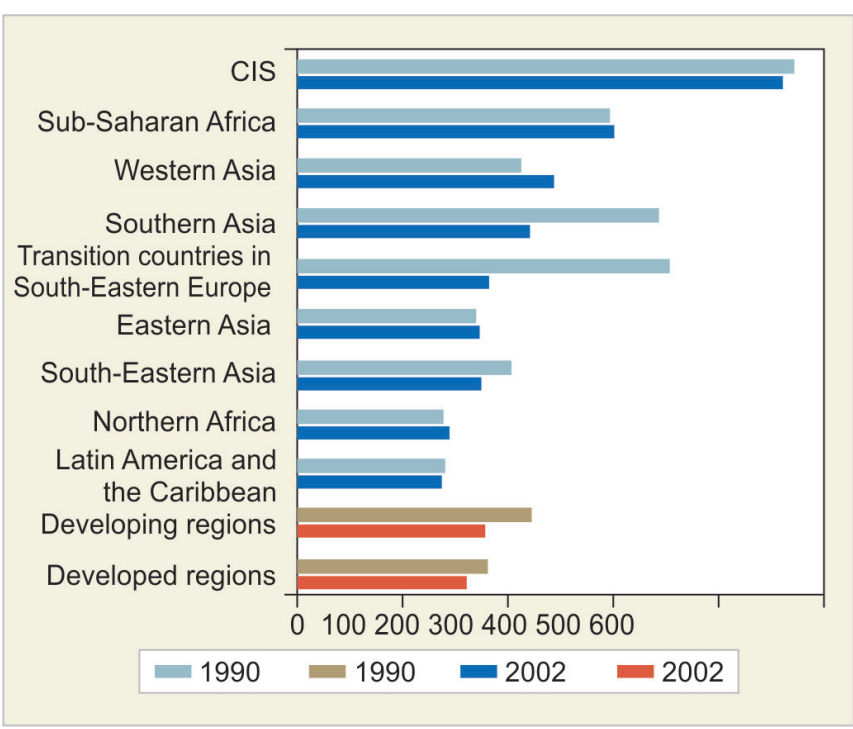

Fig. 17: Energy use per unit of gross national product, 1990 and $2002^{1}$

that a number of global conferences had taken place and the main objectives of the development agenda had been defined. ${ }^{1}$

To this end, activities will need to focus on the training of national statistical staff, while at the same time ensuring that trained statisticians remain in national statistical offices. ${ }^{1}$ Basic data collection programs must also be developed to ensure a continuous flow of social and economic statistics and increased collaboration, and knowledge-sharing must be promoted across countries within regions. ${ }^{1}$

Described UN report is finishing with the important messages:

Today's is the first generation with the resources and technology to make the right to development a reality for everyone and to free the entire human race from want. There is a shared vision of development.

The MDG, which range from halving extreme poverty to putting all children into primary school and stemming the spread of infectious diseases such as HIV/AIDS, all by 2015, have become globally accepted benchmarks of broader progress, embraced by donors, developing countries, civil society, and major development institutions alike.

These goals can be met by 2015 — but only if all involved break with business as usual and dramatically accelerate and scale up action now. ${ }^{1}$

\section{Work in Progress}

World Association of Perinatal Medicine, International Academy of Perinatal Medicine, Fetus as a Patient and lan Donald School as four sister nonprofit societies are planning a long-term activities involving maximally perinatologists all over the World. We all are nonprofit societies and naturally do not have money to build new hospitals somewhere in developing World. However, it has to be said that humanitarian agency Matres Mundi already built up hospital in Addis Ababa and School of Perinatal Medicine. We will very strongly support these new institutions. Indeed, our greatest power are human resources and excellent teachers we have within our societies. A detailed plan has been made for year 2020. We will mention most important events:

International symposium in Khartoum (Sudan), February 27, 2020, where we will discuss problem of proper education of future

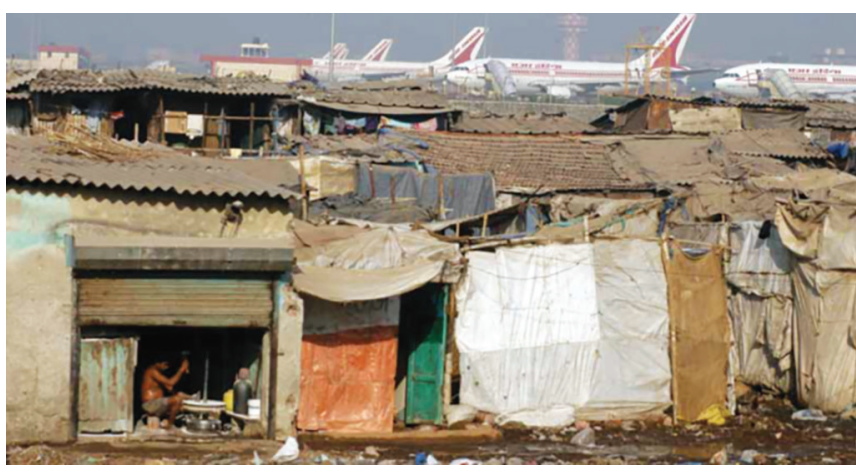

Fig. 18: Poor living conditions near modern airport in developing country ${ }^{1}$

teachers in the action of reducing maternal mortality. Apart from six internationally recognized speakers, we will have even more from surrounding countries and Sudan.

To Sudan and Nigeria, Donald School will send 10 copies of Textbook of Perinatal Medicine as a gift. Our members will be in future encouraged to donate used books to our colleagues in countries in need. Special issue of Yellow Journal is just finished and includes 11 chapters from the known authors from developing countries and will be distributed to future teachers and other colleagues in Sudan.

In continuation of the meetings we are planning to have several appropriate presentations at the well-established meeting in Sardinia in June 2020. Most significant event will be 10 World Congress of Perinatal Medicine in developing countries to be held in Sarajevo and Tuzla, Bosnia and Herzegovina, October 1-4 this year. It is planned to invite many ministries from developing countries and ambassadors represented in Bosnia and Herzegovina. Some public sessions are planed where citizens will be invited to be informed of this tragic episode.

Special issue of Yellow Journal will publish selected articles on reduction of maternal mortality.

Those are activities planned for 2020, but we have many ideas for the period after 2020 and most sincerely do invite all of you to contribute with your own even modest papers. It is hoped that this global activities will at least inform properly public and institutions about tragedy in developing countries for which we in developed World should feel ashamed.

\section{What has beEn Learned fROM the Millennium Development Goal Report 2015?}

Ten years after the first extensive MDG report from 2005, ${ }^{1}$ a new report has been published in 2015, the year which was designated as the final year for reaching the MDG achievements. ${ }^{2}$

\section{Goal I: Eradicate Extreme Poverty and Hunger}

As it is shown in Figure 19, global poverty has reached the MDG target of $50 \%$ reduction (from $36 \%$ in 1990 to $15 \%$ in 2011) of people living on less than $\$ 1.25$ a day in the past 20 years, which happened in 2011, 5 years ahead of the 2015 deadline. ${ }^{2}$

The most populous countries India and China played a key role in the impressive reduction of poverty in the regions of Southern Asia from 52\% (1990) to 17\% (2015), and for the same years in Eastern Asia, the decline was from 61 to $4 \% .^{2}$ The poverty is still high in 


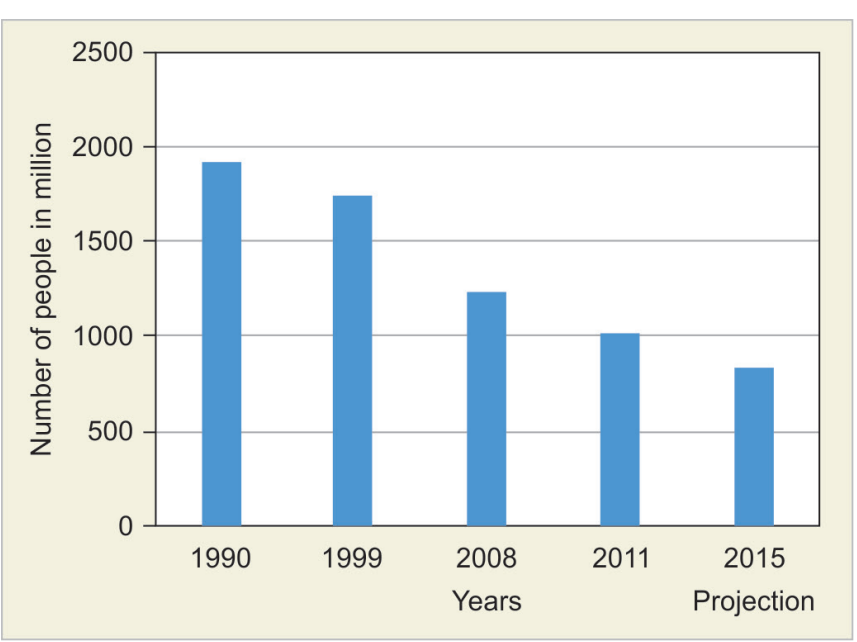

Fig. 19: Number of people living on less than $\$ 1.25$ a day worldwide, 1990-2015 (million) (modified according to ref. 2)

sub-Saharan Africa where reduction rate in the period of 20 years was only $28 \%$ (from $57 \%$ in 1990 to $41 \%$ in 2015), and it is expected to increase in Western Asia between 2011 and 2015 (from 2 to 3\%). ${ }^{2}$ Women are faced with greater risk to live in poverty. ${ }^{2}$

Hunger is still a problem in developing region where the percentages of undernourished people dropped from $23 \%$ in 1990 to $13 \%$ in developing World. ${ }^{2}$ In some regions (sub-Saharan Africa, Central Africa, Western Asia), the situation of undernourished people and hunger are worsening instead of improving. ${ }^{2}$ Conflicts have forced almost 60 million people from their homes. ${ }^{2}$ The eradication of poverty and hunger are the most important goals of development agenda in the post-2015 period. ${ }^{2}$

\section{Goal II: Achieve Universal Primary Education}

In developing regions, the percentage of children enrolled to primary school increased from $83 \%$ in the year 2000 to the estimate of $91 \%$ in the year $2015 .^{2}$ The number of children enrolled in primary school more than doubled in sub-Saharan Africa (from 67 million in the year 1990, to 149 million in the year 2012), while the number out-of-school children of primary school age worldwide has decreased from 100 million in the year 2000 to 57 million in the year $2015 .^{2}$ The literacy rate of youth between 15 years and 24 years globally increased from $83 \%$ in the year 1990 to $91 \%$ in the year $2015 .^{2}$ A considerable progress has been made in expanding primary education enrolment particularly since the adoption of the MDGs in 2000 . $^{1}$

Enormous progress has been achieved in the universal primary education in the past 15 years; however, despite good results, special attention will be needed in the post 2015-period, because the education (especially women) has the core place in the achievement of prosperity in the families and the societies. ${ }^{2}$

\section{Goal III: Promote Gender Equality and Empower Women}

There are several sectors which are important for the gender equality: education, participation in labor force, paid work outside of agriculture, and political engagement. ${ }^{2}$ Gender parity in the primary education has been achieved in about two-thirds of the countries in developing regions in the period of two decades. ${ }^{2}$ Labor force comprises three quarters of working-age men and half of working-age women. In 2015, women make $41 \%$ of paid

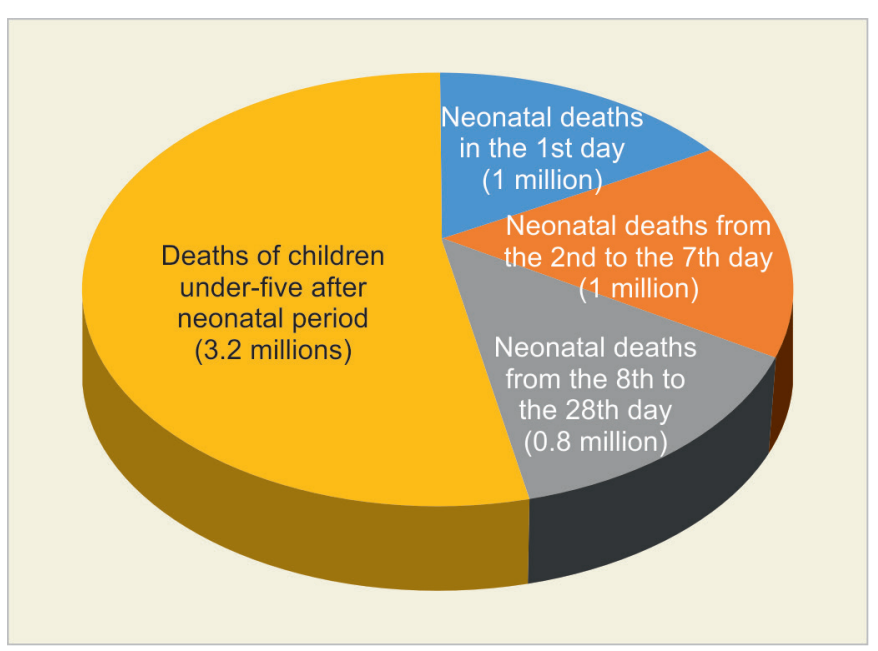

Fig. 20: Neonatal deaths as a share in 6 million under-five children deaths in the year $2015^{2}$

workers outside agriculture, which is an increase compared to $35 \%$ in the year $1990 .^{2}$ Only $20 \%$ of women are recently members of the parliament, which an is increase from the $10 \% 20$ years ago. ${ }^{2}$ The fundamental causes of inequality between men and women should be rectified in the next period. Gender equality perspectives should be integrated fully into all goals of the post-2015 development agenda. $^{2}$

\section{Goal IV: Reduce Child Mortality}

Still, 6 million children under-five die in 2015 due to preventable causes, which is much less than in 1990 when the number of deaths was 12.7 million. ${ }^{2}$ It has been estimated that death rate of under-five children decreased from 90 to 43 per 1,000 between 1990 and 2015, which is more than $50 \%$ in all regions except Oceania. ${ }^{2}$ Regardless of such improvements, it will take another 10 years to meet the global MDG target. About 16,000 children under five continue to die every day in 2015, and most of them in the first day of life, the first week of life and the first month of life. ${ }^{2}$ In sub-Saharan Africa, under-five mortality rate has decreased from 179 to 86 deaths per 1,000 live births which is 3 million under-five children a year which is half of the global under-five deaths in the World. ${ }^{2}$ The problem is that in this region the population of under-five children is expected to rise in the next decades, which means that the mortality in absolute numbers will also increase. ${ }^{2}$

In the period from 1990 to 2015 , worldwide neonatal mortality decreased from 33 to 19 deaths per 1,000 live births, which was much slower decline than for children aged 1-59 months, which is the reason why in the after-2015 period every region in the World will have more neonatal deaths within the total under-five children deaths. ${ }^{2}$ Of around 6 million under-five children who die in 1 year, one million die in the first day of life, another one million in the first week and 0.8 million will die after the first week of life, which is 2.8 million neonates who die in the first 4 weeks of life (Fig. 20). ${ }^{2}$ Most of neonates die (35\%) because of complications of preterm birth, additional $24 \%$ because of the complications during birth and delivery, and sepsis is cause of death for $15 \%$ of neonates (Fig. 21). ${ }^{2}$ Many neonatal deaths are avoidable with simple and cost-effective interventions around the time of birth, which are frequently missed by many newborns and the mothers. ${ }^{2}$

Although in sub-Saharan Africa under-five mortality rate is still high in 2015 ( 86 per 1,000 live births), the rate of decline in the 


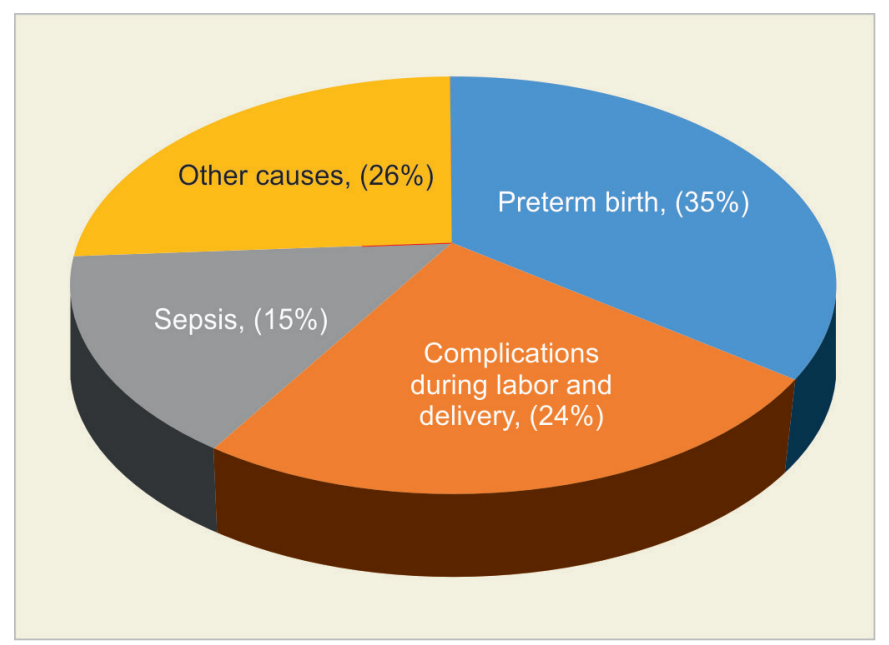

Fig. 21: Causes of neonatal deaths in $2015^{2}$

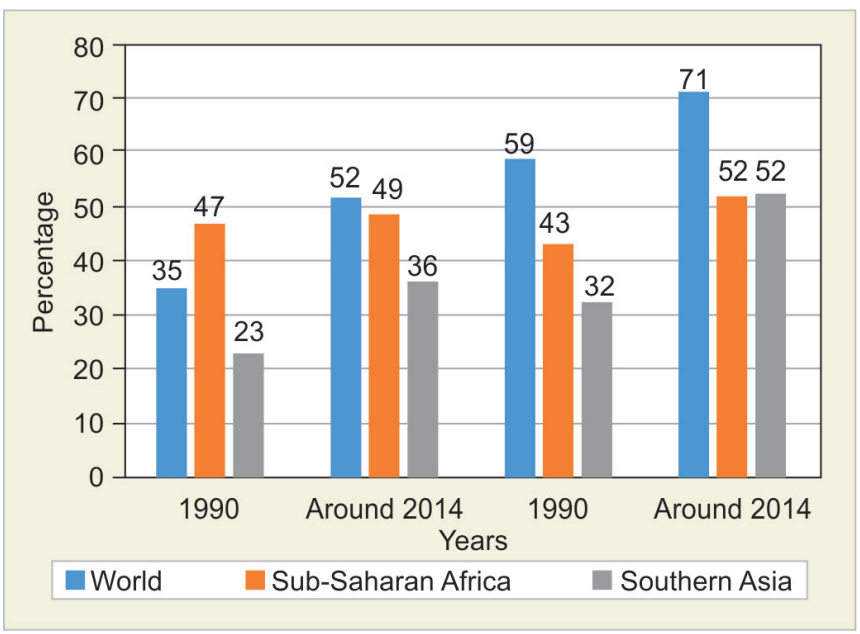

Fig. 23: Disparities between some WHO regions in antenatal visits and coverage by skilled birth attendant in the year 1990 and around the year $2014^{2}$

period 2005-2013 (4.2\% per year) is five times faster than it was in the period 1990-1995 (0.8\% per year). ${ }^{2}$ Interestingly, since 1995 in high-income countries the annual reduction rate of under-five mortality was not accelerating, while it has accelerated in lower income countries. Supporting decrease of under-five mortality should target the children from poorest households and from rural areas, and supporting women's education should be a part of this empowerment. $^{2}$

There is still a long way to go in terms of decreasing underfive mortality rate with particular emphasis on the decrement of neonatal mortality in all the World and especially in developing and poor countries. With millions of women and children still at risk of dying of preventable causes, maternal, newborn, and child survival must remain at the heart of the post-2015 global development agenda. $^{2}$

\section{Goal V: Improve Maternal Health}

Maternal mortality dropped for $45 \%$ from the year 1990 till the year 2013 (from 380 maternal deaths to 210 per 100,000 live born, as shown in Figure 22). ${ }^{2}$ The regions with highest maternal mortality experienced high decrease of maternal mortality for $64 \%$ (from

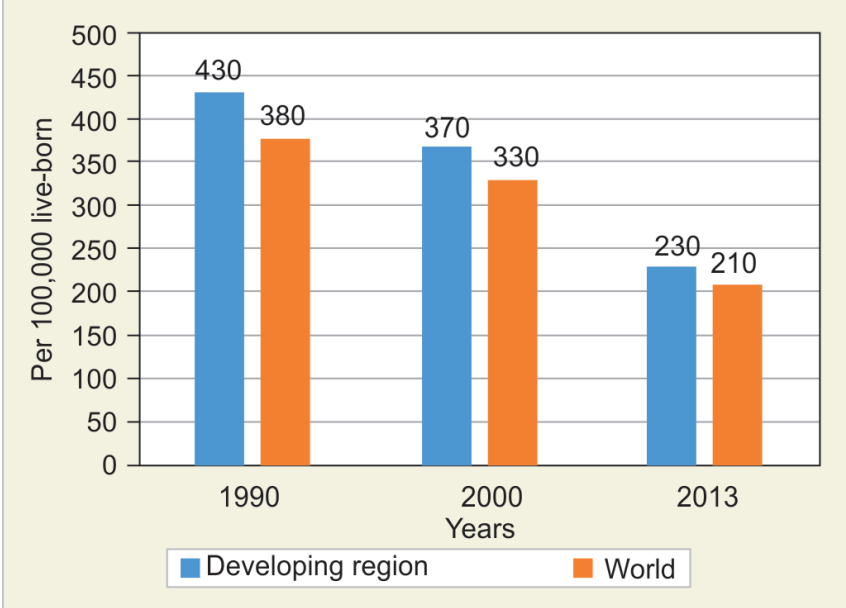

Fig. 22: Changes of maternal mortality rate (maternal deaths per 100,000 live-born) from 1990 to 2013 in developing countries and in the World ${ }^{2}$

530 to 190 per 100,000 live-born) in Southern Asia, and $49 \%$ in sub-Saharan Africa (from 990 to 510 per 100,000 live-born). ${ }^{2}$ This relative improvement is tremendous if we compare it with only $37 \%$ of decrease (from 26 to 16 per 100,000 live-born) in developed countries, but if the rates are compared, that the data from developing World are terrifying and distressing. In 2013, still there were 800 women dying every day, which gives 289,000 women's deaths every year. ${ }^{2}$

Maternal deaths are concentrated in sub-Saharan Africa and Southern Asia, which together accounted for $86 \%$ of such deaths globally in $2013 .^{2}$

Most of maternal deaths are preventable, and based on data from the years 2003 to 2009, obstetric bleeding was the cause of death in $27 \%$ of the mothers in developing and $16 \%$ in developed regions of the World. ${ }^{2}$ Among other causes of maternal deaths, the most important are infections, high blood pressure during pregnancy and unsafe abortion and complications from delivery. ${ }^{2}$ Only $51 \%$ of countries globally (in sub-Saharan Africa only $20 \%$ ) had some data on maternal deaths, which is worrying. ${ }^{2}$

To prevent maternal deaths, the key measures are prenatal care (according to $\mathrm{WHO}$, at least four antenatal care visits in pregnancy) and support during labor and delivery by skilled birth attendants (medical doctor, nurse, or midwife) (Fig. 23). ${ }^{2}$ The progress in antenatal care has been very slow in the last 25 years in developing countries. ${ }^{2}$ The difference between 1990 data and 2014 are just $17 \%$ increase in 2014 from 35\% to 52\% of women receiving antenatal care. $^{2}$ Very slow progress has been noted in sub-Saharan Africa from 47 to $49 \%$ of women in the same period, while in Southern Asia, only $36 \%$ of women received four or more antenatal visits around the year $2014 .{ }^{2}$ Assist of the skilled birth attendant in the last 25 years has been very modest, meaning that access to care was far from being universal. ${ }^{2}$ The raise was only $22 \%$ from 1990 (59\%) to around 2014 (71\%) globally. ${ }^{2}$ Disparities between the regions in developed countries are even more profound from 100\% in Eastern Asia, $96 \%$ in Caucasus, and Central Asia to only $52 \%$ in sub-Saharan Africa and Southern Asia. ${ }^{2}$

Another important indicators of maternal health are birth rate of adolescent mothers and use of contraceptives. The birth rate of the mothers aged 15-19 years has decreased from 59 per 1,000 girls in 1990 to 51 births per 1,000 girls in $2015 .^{2}$ The highest birth rate of adolescent mother has been noted in sub-Saharan Africa, which was 
in 2015116 births per 1,000 girls (used to be 123 per 1,000 births in 1990). ${ }^{2}$ The use of contraceptives is important because it prevents number of unintended pregnancies and unsafe abortions. ${ }^{2}$ The use of married women or women in stable union in reproductive age (15-49 years of age) using contraception increased from $55 \%$ in 1990 to $64 \%$ in $2015 .^{2}$ Although in sub-Saharan Africa the use of contraception more than doubled in the period from 1990 to 2015 (from 13 to $28 \%$ ), it is still low. ${ }^{2}$

What can be concluded from the data presented before is that huge inequalities in World are related to maternal deaths, and access of healthcare related to sexual and reproductive health are far from being satisfactory, although it is claimed nowadays that reproductive health should be treated as a human right. ${ }^{2}$ Women in many developing countries still do not have access to a services of acceptable quality. Another problem is unavailability of the data related to health issues and in particular to maternal and infant health, which is preventing policy makers to define priorities in order to improve maternal and child health. ${ }^{2}$

\section{Goal VI: Combat HIV/AIDS, Malaria, and Other Diseases}

Although new HIV infection decreased from 3.5 million to 2.1 million, which is $40 \%$ in the period of 14 years (between 2000 and 2013), it is estimated that 35 million people in the World still live with the HIV infection. ${ }^{2}$ It is estimated that $0.8 \%$ of people from the age group between 15 years and 49 years of age had HIV infection in the year $2013 .^{2}$ About 1.5 million new HIV infections appeared in sub-Saharan Africa in 2013, with half of them occurring just in three countries: Nigeria, South Africa, and Uganda. In 2013, about 1.5 million people died of AIDS-related illness, which is $35 \%$ decline compared to 2.4 million deaths recorded in $2005 .^{2}$ AIDS remained the number one killer in sub-Saharan Africa, and AIDS-related deaths are not decreasing in adolescents aged 10-19 years. In subSaharan Africa, still less than $40 \%$ of youth aged $15-24$ years had comprehensive correct knowledge of HIV in $2014 .^{2}$

In 2014, out of 13.6 million people receiving antireoviral therapy in the World, 12.1 million are in developing countries. Tremendous increase of 20\% happened between the years 2012 and $2013 .^{2}$

Malaria is still one of the most important health issues in developing countries in the World, regardless of the fact that 6.2 million deaths have been prevented between the years 2000 and $2015 .^{2}$ In the same period, it is estimated that the incidence of malaria decreased by $37 \%$ and global mortality rate by $58 \%{ }^{2}$ The estimated reduction rate of as high as $69 \%$ in children, the under-five in sub-Saharan Africa, contributed significantly in the reduction of under-five child mortality by two-thirds, which was the target of MDG $4 .^{2}$

It is estimated that there have been 9 million of new cases of tuberculosis (TBC) in 2013 globally. ${ }^{2}$ When transposing this to the relative number, then it is on average $1.5 \%$ a year in all regions since the year 2000 . Tuberculosis mortality decreased by $45 \%$ between 1990 and 2013, with 1.1 million deaths caused by TBC of HIV-negative people in the year 2013. ${ }^{2}$

Although much has been achieved in combating HIV, malaria, and TBC in the World in the period from 1990 to 2015, the situation is still not satisfactory and in post-2015 era, robust efforts should be made to enable sustainable development. ${ }^{2}$

\section{Goal VII: Ensure Environmental Sustainability}

Global emission of carbon dioxide has accelerated in the 20-year period from $10 \%$ between 1990 and 2000 to 38\% from 2000 to
2012. ${ }^{2}$ Although the average emission of carbon dioxide per person per year in developed regions was 10 metric tons, and only 3 tons in developing regions, the growth from 10 to $38 \%$ was driven mainly by developing regions. ${ }^{2}$

Ozone-depleting substances have been virtually eliminated, and the ozone layer is expected to recover by the middle of this century. ${ }^{2}$

Prevention of the loss of biodiversity, and maintaining food security and water supplies strengthen climate resilience and improve human health and well-being. In 2015, 91\% of the global population uses an improved drinking water source, compared to $76 \%$ in $1990 .^{2}$

Since 1990, 2.1 billion people have gained access to improved sanitation, and the proportion of people practising open defecation globally has fallen almost by half. ${ }^{2}$

The proportion of urban population living in slums in the developing regions fell from 39.4 to $29.7 \%$ between 2000 and $2014 .{ }^{2}$

In the post-2015 period, efforts should be made to ensure environmental sustainability which is the most important for continuing socioeconomic development, poverty eradication, and decreasing of inequalities. ${ }^{2}$

\section{Goal VIII: Develop a Global Partnership for Development}

Net official development assistance (ODA) from member countries of the Development Assistance Committee (DAC) of the Organization for Economic Co-operation and Development increased by $66 \%$ between 2000 and 2014. In 2014, ODA decreased by $0.5 \%$ in real terms and it reached $0.29 \%$ of DAC gross national income (GNI) in the same year, while the UN's target is $0.7 \%$ of the GNI, exceeded by Denmark, Luxembourg, Norway, Sweden, and the United Kingdom. ${ }^{2}$

Preliminary data for 2014 show that bilateral ODA to subSaharan Africa decreased by $5 \%$ ( $2 \%$ if debt relief is excluded) in real terms from the previous year, reaching $\$ 25$ billion at constant 2013 prices. $^{2}$

In the post-2015 period, ODA remains critically important for developing countries in order to implement sustainable development goals (SDGs). Most of the SDGs carry forward the matters not solved by the MDGs. ${ }^{2}$ In contrast to the MDGs, SDGs have been brought together within one framework as universal whole, with the interactions among them, which are brought into focus in the 2030 Agenda. $^{2}$ The 2030 Agenda defined 17 SDGs and 169 targets, with 232 indicators in the global framework. ${ }^{3}$

\section{Conclusion}

The first quadrennial sustainable development goal report from 2019 has been entitled "The Future is Now. Science for Achieving Sustainable Development." ${ }^{3}$ In his foreword of the document, António Guterres, UN Secretary General, pointed out: ${ }^{3}$

"Science is our great ally in the efforts to achieve the goals. The global sustainable development report 2019, prepared by an independent group of scientists, presents an objective assessment of where we are falling short and what needs to be done. The report highlights central entry points to leverage interlinkages and accelerate progress across all 17 sustainable development goals.

This report reminds us that the future is determined by what we do now and the window of opportunity is closing fast. I encourage all actors to translate the insights from this analysis into collective action." 
UN Under-Secretary-General for Economic and Social Affairs, Liu Zhenmin in the Preface of the same document stressed: ${ }^{3}$

"The Report makes clear that we are at risk of irreversibly degrading the natural systems that sustain us and further points out where we are off track in "leaving no one behind." More ambitious, more transformative and more integrated responses are urgently needed."

Former Norway Prime Minister, Gro Hrlem Bruntland in the prologue to the report rightly so wrote: ${ }^{3}$

"We need courage to confront the vested political, business and economic interests that seek to maintain the current unequal order, and we need to grasp the opportunity that the move to a low carbon economy offers in order to rectify current inequalities.

We need to promote agreement, inclusivity and consensus to achieve policies that work for the common good, rather than narrow self-interest, across both the public and the private sectors.

And we need to inspire hope across all sections of society, especially among young people, letting them know that their voices will be heard, their experiences will be acknowledged and their ideas will be anchored in the policymaking process. The data and the proposals in the present report are critical elements in society's armory in the fight against climate change, poverty and injustice."

Many of the SDGs carry forward the unfinished business of the MDGs, while several others can be traced back to the objectives already agreed to in different United Nations forums. ${ }^{2,3}$ In the pursuit of the MDGs, the global community achieved many successes, but also fell short in several ways as it learned important lessons about the opportunity of cobenefits, and the inevitability of trade-offs and tough choices. ${ }^{3}$ As it was shown, most of MDGs were not met, which was disappointing and distressing for the whole community, and for the community of perinatologists, it was worrying that goals IV and V were far behind the proclaimed targets. One of the reasons was that global prominent societies of fetomaternal specialists and neonatologists were not consulted or engaged to solve the problems of maternal and child mortality. In the regions like India, where Federation of Obstetrics and Gynecology of India was engaged, substantial progress in decreasing maternal and infant mortality has been achieved. ${ }^{4}$ Besides that, MDGs were not brought together within one framework, which is not the case with SDGs. ${ }^{3}$ The emphasis on the interactions between SDGs was influenced by the growing scientific understanding of the Earth as a closely linked human-environment system.

The four levers of change-governance, economy and finance, individual and collective action, and science and technology-should be coherently deployed and combined to bring about transformational change. ${ }^{3}$ All actors should strive for coordinated efforts and prioritize policy coherence and consistency across sectors. ${ }^{3}$ Every country and region should design and rapidly implement integrated pathways to sustainable development that correspond to their specific needs and priorities and contribute also to the necessary global transformation. ${ }^{3}$

As far as our learned societies are concerned, we already made strong start. It is proper to finish this overview with strong message of American president Roosevelt at the time of horrible American economical crisis: "Gentlemen, begin best you can, but begin!"

We did so.

And to quote another big person Winston Churchill: "This is not the end. It is not even the beginning of the end. This is the end of the beginning."

\section{References}

1. United Nations. Millennium Development Goals Report, 2005. United Nations: New York; 2005. https://unstats.un.org/unsd/mi/ pdf/MDG\%20Book.pdf, Accessed on January 04, 2020.

2. United Nations. Millennium Development Goals Report, 2015. United Nations: New York; 2015. https://www.un.org/millenniumgoals/2015 MDG_Report/pdf/MDG\%202015\%20rev\%20(July\%2015).pdf, Accessed Jan 04, 2020.

3. Independent Group of Scientists appointed by the Secretary-General. Global Sustainable Development Report 2019: The Future is Now Science for Achieving Sustainable Development. United Nations: New York; 2019. https://sustainabledevelopment.un.org/content/ documents/24797GSDR_report_2019.pdf, Accessed January 3, 2020.

4. Mohapatra A, Gomare M. A critical appraisal of the maternal and child health scenario in a metropolitan city in India with reference to achievements of millennium development goals. J Family Med Prim Care 2019;8(3):995-1001. DOI: 10.4103/jfmpc.jfmpc_379_18. 